\title{
The National Ignition Facility Incorporates P2/E2 in Aqueous Parts Cleaning of Optics Hardware
}

Katharine A. Gabor

July 27, 2001

U.S. Department of Energy

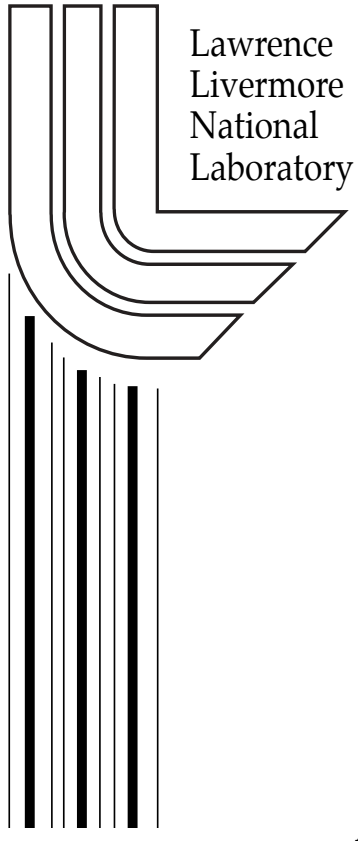




\section{DISCLAIMER}

This document was prepared as an account of work sponsored by an agency of the United States Government. Neither the United States Government nor the University of California nor any of their employees, makes any warranty, express or implied, or assumes any legal liability or responsibility for the accuracy, completeness, or usefulness of any information, apparatus, product, or process disclosed, or represents that its use would not infringe privately owned rights. Reference herein to any specific commercial product, process, or service by trade name, trademark, manufacturer, or otherwise, does not necessarily constitute or imply its endorsement, recommendation, or favoring by the United States Government or the University of California. The views and opinions of authors expressed herein do not necessarily state or reflect those of the United States Government or the University of California, and shall not be used for advertising or product endorsement purposes.

This work was performed under the auspices of the U. S. Department of Energy by the University of California, Lawrence Livermore National Laboratory under Contract No. W-7405-Eng-48.

This report has been reproduced directly from the best available copy.

Available electronically at http://www.doc.gov/bridge

Available for a processing fee to U.S. Department of Energy

And its contractors in paper from

U.S. Department of Energy

Office of Scientific and Technical Information

P.O. Box 62

Oak Ridge, TN 37831-0062

Telephone: (865) 576-8401

Facsimile: (865) 576-5728

E-mail: reports@adonis.osti.gov

Available for the sale to the public from

U.S. Department of Commerce

National Technical Information Service

5285 Port Royal Road

Springfield, VA 22161

Telephone: (800) 553-6847

Facsimile: (703) 605-6900

E-mail: orders@ntis.fedworld.gov

Online ordering: http://www.ntis.gov/ordering.htm

\section{OR}

Lawrence Livermore National Laboratory

Technical Information Department's Digital Library

http://www.llnl.gov/tid/Library.html 


\section{The National Ignition Facility Incorporates P2/E2 in Aqueous Parts Cleaning of Optics Hardware}

When completed, Lawrence Livermore National Laboratory's (LLNL) National Ignition Facility (NIF) will be the world's largest laser with experimental capabilities applicable to stockpile stewardship, energy research, science and astrophysics. As construction of the conventional facilities nears completion, operations supporting the installation of specialized laser equipment have come online. Playing a critical role in the precision cleaning of mechanical parts from the NIF beamline are three pieces of aqueous cleaning equipment. Housed in the Optics Assembly Building (OAB), adjacent to NIF's laser bay, are the large mechanical parts gross cleaner (LMPGC), the large mechanical parts precision cleaner (LMPPC), and the small mechanical parts gross and precision cleaner (SMPGPC).

These aqueous units, designed and built by Sonic Systems, Inc., of Newtown, Pennsylvania, not only accommodate parts that vary greatly in size, weight, geometry, surface finish and material, but also produce cleaned parts that meet the stringent NIF cleanliness standards (MIL-STD-1246C Level 83 for particles and $\mathrm{A} / 10$ for non-volatile residue). Each unit was designed with extensive water- and energy-conserving features, and the technology used minimizes hazardous waste generation associated with solvent wipe cleaning, the traditional method for cleaning laser mechanical components.

The LMPGC (Figure 1) provides preliminary gross cleaning for large mechanical parts. Collection, filtration and reuse of the wash and primary rinse water in the LMPGC limit its routine discharge to the volume of the low-pressure, deionized secondary rinse.

After an initial gross cleaning in the LMPGC, a large mechanical part goes to the LMPPC (Figure 2). This piece of equipment, unique because of its size, consists of four 2700-gallon tanks. Parts held securely on specialized metal pallets (jointly weighing up to 1500 pounds) move through the tanks on an automated system. Operators program all movement, speeds and process times to optimize parts cleaning. The cleaning line is as follows:

- Ultrasonic wash tank with an automatic feed to maintain surfactant concentration and $\mathrm{pH}$. One hundred percent of the wash solution is filtered and reused. This wash bath needs changing only twice a year.

- Pre-rinse spray area. Here an initial low-volume rinse removes most of the wash solution, preserving the cleanliness of the immersion rinse tank. Effluent from this process, less than $1 \%$ of the total volume used in a wash cycle, is the LMPPC's only regular discharge during a normal wash cycle.

- Immersion rinse tank with ultrasonics. All of the deionized rinse water is filtered and re-polished for reuse. Reusing the deionized water also saves energy by taking advantage of previously heated water.

- Final spray rinse. All of this water is filtered, re-polished and reused. 
- Drying area. Hot, HEPA-filtered air, which dries the part, is filtered and re-circulated to conserve energy.

The SMPGPC, essentially a scaled-down version of the LMPPC, handles parts weighing up to $300 \mathrm{~kg}$. The SMPGPC has smaller tanks (200 gallons) and a smallparts gross-cleaning system at the front end of the cleaning line.

Both the SMPGPC and LMPPC are surrounded by enclosures that reduce ambient room noise, provide a safety barrier, and help maintain the cleanliness of the area.

Additional energy-saving features of the LMPPC and SMPGPC include:

- Double-walled, insulated tank walls to minimize the energy needed to maintain bath temperature

- Lids that cover the tanks at all times, except when a pallet is being moved between them.

- Ultrasonic transducers, spray nozzles, and hot-air nozzles in the LMPPC are mounted on programmable trolleys, measuring approximately onefifth of the tank length. Effective cleaning, rinsing and drying are achieved, because the trolley is programmed to focus only those areas necessary, eliminating the need for transducers and other fixtures to line the entire wall of a tank. This design allows adaptability for a wide variety of part sizes and configurations, and prevents energy waste by focusing transducer energy on areas where it is most needed.

According to OAB Operations Manager Gary Edwards, the SMPGPC and LMPPC units, in operation for one year and six months respectively, have functioned exceptionally well. "We have several process development efforts underway to maximize cleaning efficiencies and take advantage of the parts cleaners' features," said Edwards. "This equipment is going to be critical to meeting schedule and throughput requirements for NIF hardware."

Contact Katharine Gabor, Lawrence Livermore National Laboratory, (925-422-9790) or kgabor@llnl.gov 


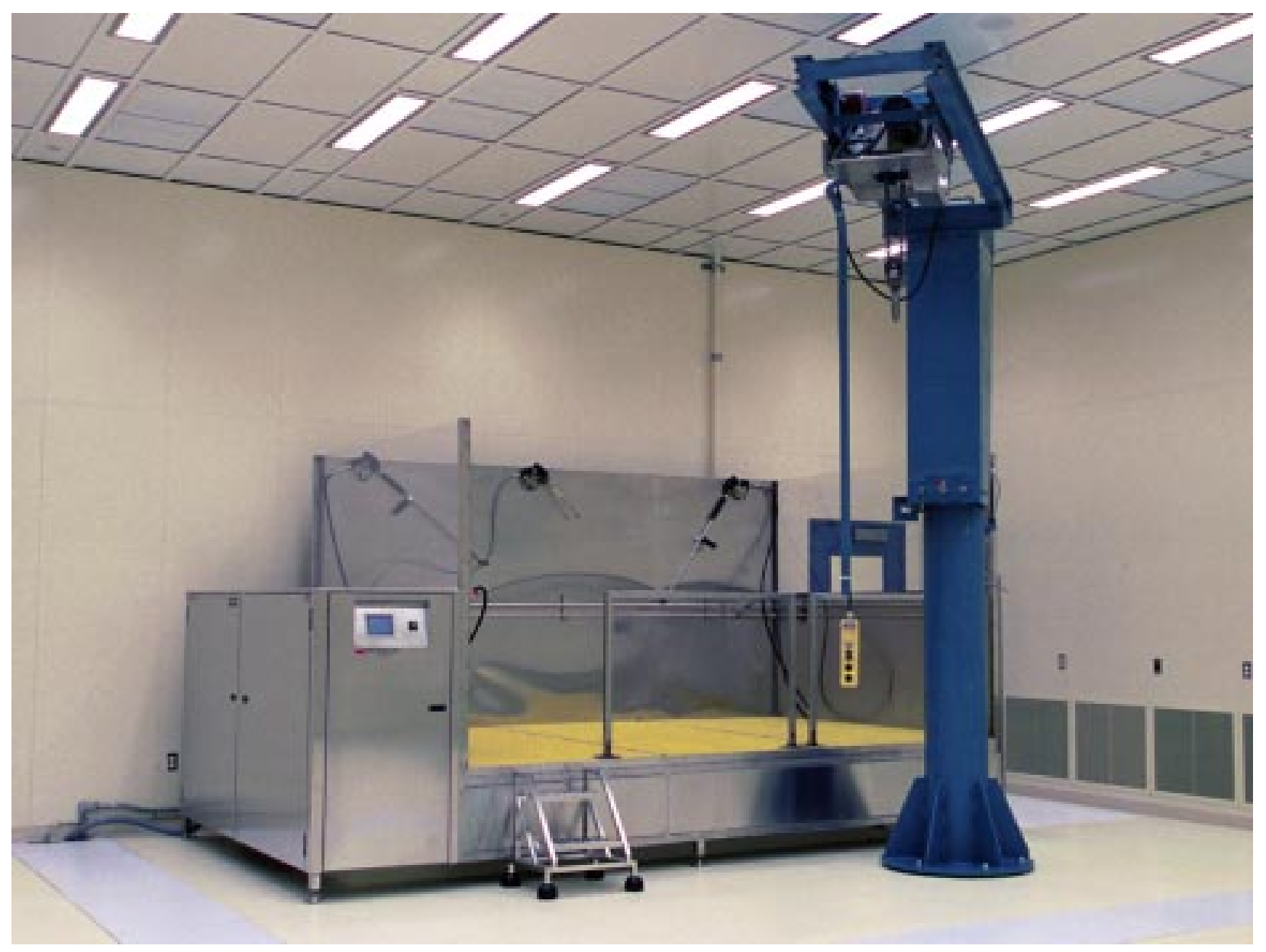

Figure 1: Critical mechanical parts used in the NIF receive a preliminary cleaning in the large mechanical parts gross cleaner designed by Sonic Systems, Inc. 


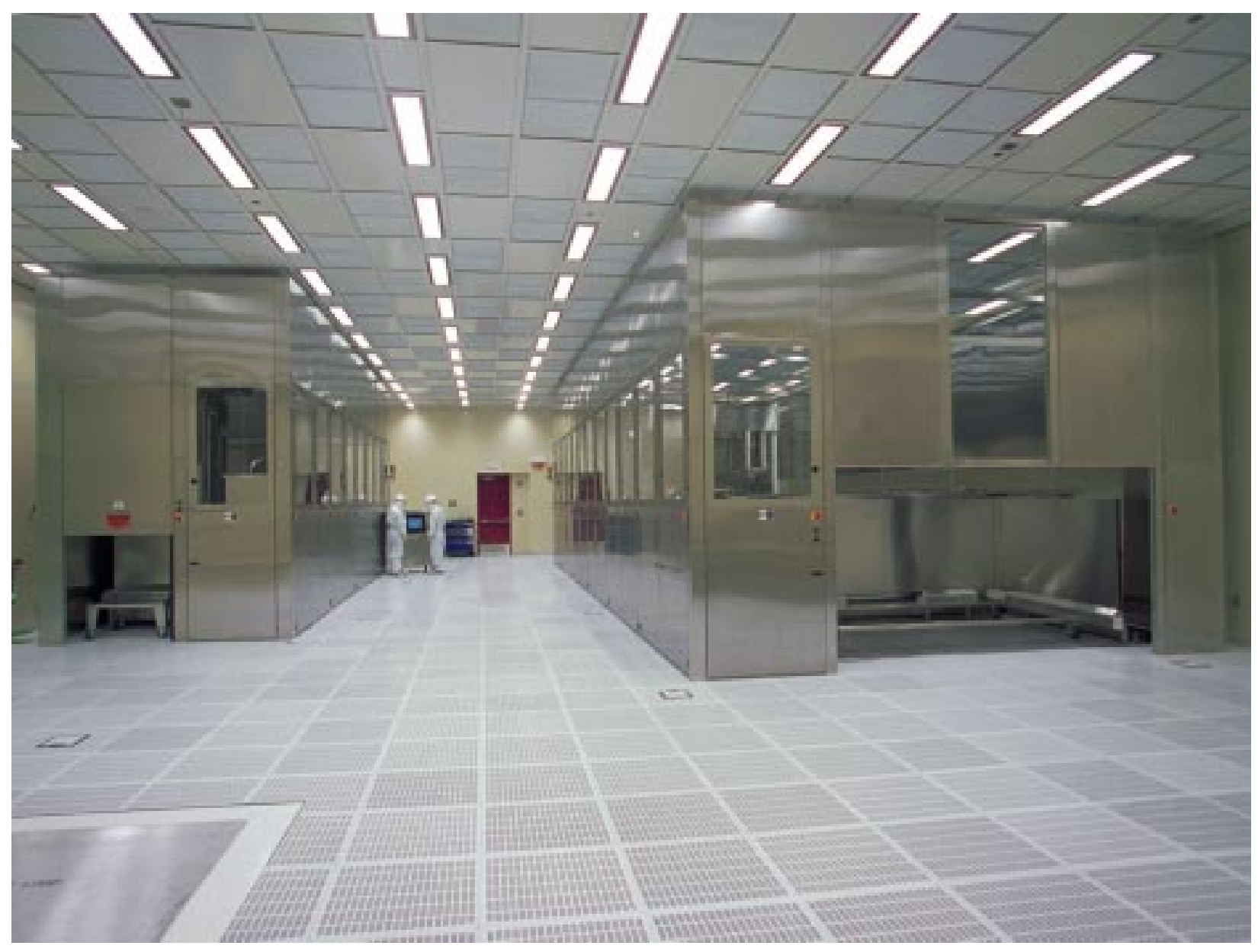

Figure 2: Depending on their size, NIF mechanical parts receive final cleaning in either the large mechanical parts precision cleaner (right) or the small mechanical parts gross and precision cleaner (left). The parts cleaners were designed by Sonic Systems, Inc. 